\title{
AUSCULTATORY AND PHONOCARDIOGRAPHIC FINDINGS IN HEALTHY CHILDREN WITH SYSTOLIC MURMURS
}

\author{
BY \\ AUBREY LEATHAM, BERNARD SEGAL,* AND HAROLD SHAFTER \\ From St. George's Hospital and the Institute of Cardiology, National Heart Hospital, London
}

Received November 9, 1962

Systolic murmurs in healthy children are common and occasionally cause difficulty in differential diagnosis. Our main object has been to make a graphic study of these murmurs in relation to rightand left-sided cardiac events and discuss their differentiation from organic murmurs. The opportunity has been taken to give some normal measurements used routinely in phonocardiography in our department.

Basal ejection vibrations can be recorded with electronic amplification in most normal subjects (McKee, 1938), and any slight increase in their intensity makes them audible with the stethoscope. The murmur is soft (at rest) and short, finishing well before the second sound, usually similar in intensity at the pulmonary area, left sternal edge, and mitral area, and often possessing a grunty or musical quality (Still, 1909; Harris and Friedman, 1952; Harris, 1955; Lessof and Brigden, 1957; Wells, 1957): it is frequent in children, becoming louder with increased stroke flow from exertion, excitement, and bradycardia, or associated with hyperkinetic states, and tends to disappear after puberty. Differentiation of this physiological ejection murmur (Mannheimer, 1940) from a pansystolic regurgitant murmur is easy because the ejection murmur finishes before its valve closure sound. The difficulty is to decide whether an ejection murmur is truly physiological, or due to increased stroke flow from a regurgitant aortic or pulmonary valve or left-to-right shunt, or due to stenosis, or simply to minimal valve distortion or roughening (e.g. acute rheumatic valvulitis, mild chronic valvulitis, bicuspid valve). Pulmonary stenosis and left-to-right shunting atrial septal defect can be excluded at once by analysing the effect of continued respiration on the second heart sound, and minimal damage to this valve without stenosis or regurgitation is extremely rare. An aortic systolic murmur may be more difficult to assess, and it had been hoped to obtain information by timing the onset and peak of the murmur in relation to aortic and pulmonary ejection.

Phonocardiograms taken simultaneously with the electrocardiogram and carotid pulse have been used to give an indication of the normal electromechanical interval of the left ventricle, isometric time, and duration of ejection.

\section{METHOD}

The local doctors, particularly in the schools, were asked to refer all children with systolic murmurs, and 80 healthy children were selected with normal chest radiograph, electrocardiogram, and hæmoglobin. Of these, 20 children ranged in age from 3 to 5 years, 25 children from 6 to 10 years, and 35 from 11 to 16 years. The systolic murmur was always soft at rest, usually grade 2 (of Levine's six grades), occasionally grade 3. The murmur was short and was not accompanied by any abnormal signs. To minimize the risk of including abnormal murmurs, the children were seen by each investigator, and were re-examined in one year and some-

* Post-doctoral Fellow, National Heart Institute, United States Public Health Service. Present address Hahnemann Hospital, Philadelphia. 
times each year for five years. The inclusion of abnormal children was further diminished by performing cardiac catheterization in six with doubtful physical signs, and by excluding children with ejection sounds.

Phonocardiograms were recorded simultaneously from two sites, together with the carotid pulse, respiration, and electrocardiogram (Leatham, 1952) on a four-channel photographic recorder made by the Cambridge Instrument Company of England. The paper speed was $100 \mathrm{~mm}$. per second, and the galvanometers used for sound responded uniformly from 30 to 800 cycles per second.

Measurements were made from the onset of electrical activation (QRS) to the onset of the first major high frequency components of the first sound assumed to be due to mitral closure (M1), as an indication of the electromechanical interval of the left ventricle. When possible, measurements were made between the mitral and tricuspid components (T1) of the first heart sound, and between mitral closure and the beginning of carotid rise (corrected for delay) as an indication of the left ventricular isometric contraction time. Special attention was given to the splitting of the two components of the second heart sound (A2 and P2) during the respiratory cycle, and measurements were made of the magnitude of each in the pulmonary area. The murmurs were recorded in all areas with both high and medium frequency filters, and the time measured from mitral closure to the beginning, peak, and end of the murmur. The frequency of the vibrations was measured by counting, with the help of a hand lens, the number of waves in one-tenth second.

The carotid pulse tracings were taken in each subject by a method that corresponded closely to the central aortic pulse, using an air-filled cuff and a linear manometer and amplifying system (Duchosal et al., 1956; Robinson, 1963). Measurements were made from the onset of electrical activation (QRS) to carotid rise, corrected for delay in the system by subtracting the interval between A2 and the dicrotic notch. The variations of the carotid ejection time with heart rate were determined in each tracing during expiration.

\section{RESULTS}

First Heart Sound. Splitting of the first heart sound into two major high frequency components, assumed to be due to mitral and tricuspid closure, was demonstrated in 40 of the 80 children (Fig. 1), and was usually most obvious at the lower end of the sternum, probably because this site was nearest to the relatively softer tricuspid component. The interval separating the two components averaged 0.02 second (range $0.01-0.04$ second), and mitral closure appeared to precede tricuspid closure as in adults, judged by the site of maximal intensity of these sounds and their relation to the carotid pulse (Leatham, 1954). The precedence of left ventricular contraction over right has been confirmed by the findings of electrokymography (Reinhold and Rudhe, 1957) and by direct pressure pulses from the ventricles in a few cases (Braunwald, Fishman, and Cournand, 1956). In the other 40 children no splitting of the first sound could be demonstrated.

The interval between the onset of QRS and of mitral closure (Table I) averaged 0.04 to 0.05 second, shorter for younger children than adolescents, and would be expected to be an indication of the electromechanical interval of the left ventricle: it compares with the figure of $0.055 \mathrm{sec}$. found by Weissler, Leonard, and Warren (1958) and of 0.052 found by Braunwald et al. (1956) between the onset of QRS and the crossing of left ventricular and left atrial pressure curves.

The interval between mitral closure and carotid rise was expected to give an indication of the isometric contraction time of the left ventricle and measured from 0.02 to $0.05 \mathrm{sec}$. with a mean of $0.03 \mathrm{sec}$. (Table I). Wiggers and Clough (1919) made an estimate of from 0.025 to 0.08 sec. (mean of 0.05 in adults) using simultaneous heart sounds and indirect subclavian pulse tracings. Braunwald et al. $(1955 ; 1956)$ made direct measurements from left ventricular and aortic pulses in normal subjects and found isometric times varying from $0.04-0.06 \mathrm{sec}$. Our estimate of a slightly shorter isometric time might be explained by youth and by a delay between the onset of rise of pressure in the left ventricle and shutting of the mitral valve; in fact we found a delay of $0.01 \mathrm{sec}$. (additional catheter delay of $0.005 \mathrm{sec}$. has been subtracted) in eight adults with aortic stenosis in whom we had obtained left ventricular pulses simultaneously with heart sounds.

Second Heart Sound. In the expiratory phase of continued respiration there was a single second sound in the pulmonary area in 54 children, and close splitting of from 0.01 to $0.02 \mathrm{sec}$. in the remaining 26 (Fig. 1). During inspiration the width of the splitting invariably increased, depending mainly on the depth and rate of respiration, measuring from 0.02 to $0.07 \mathrm{sec}$. Analysis of the 


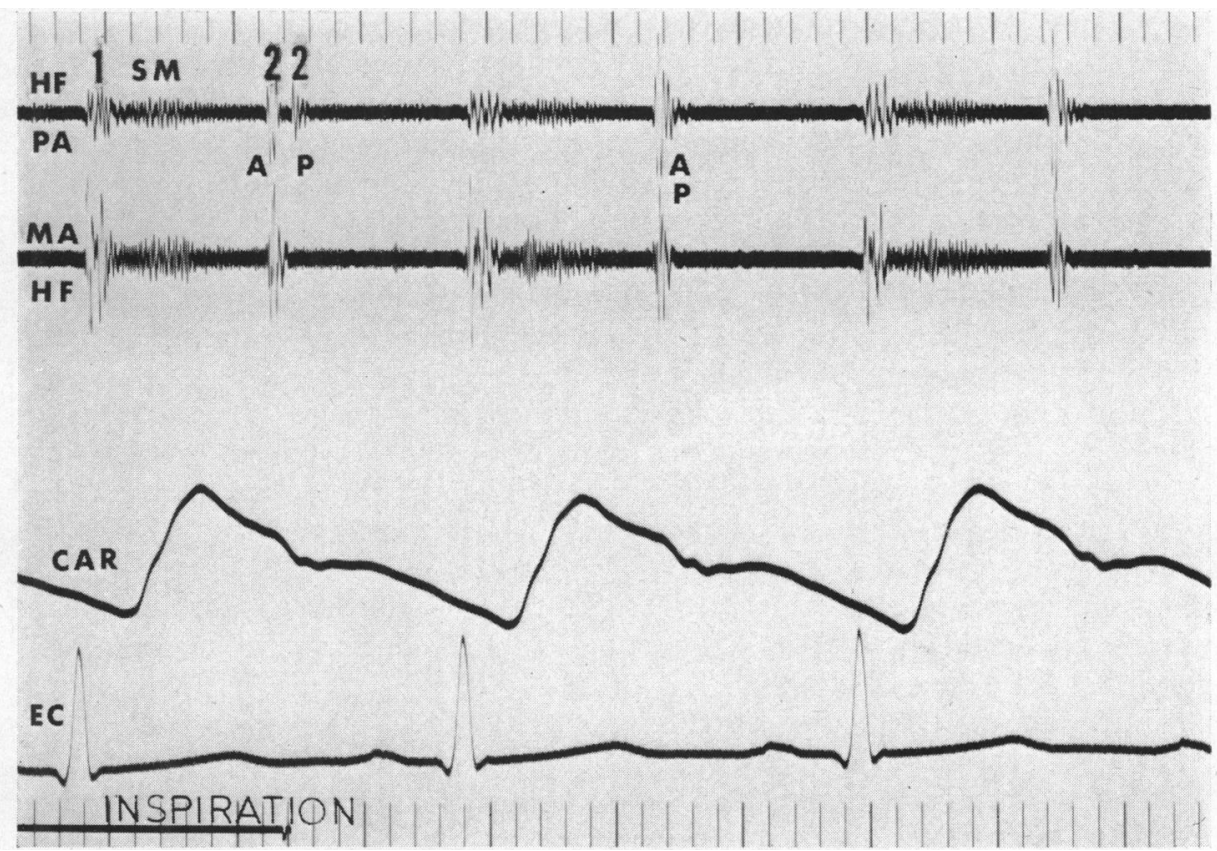

FIG. 1.-Healthy child: high frequency phonocardiogram (HF) resembling auscultation from the pulmonary area (PA), and mitral area (MA). Simultaneous indirect carotid pulse (CAR) and electrocardiogram (EC). Splitting of the second sound in the pulmonary area into aortic (A) and pulmonary (P) components during inspiration while the second sound at the mitral area is solely due to aortic closure. The physiological ejection systolic murmur (SM) ends before the second sound. The time intervals in this and subsequent records are 0.04 sec.

two components during inspiration showed that, as in healthy adults, aortic closure always preceded pulmonary and was widely transmitted to all areas. The pulmonary closure sound was less intense than the aortic, even in the pulmonary area (except in 10 older children), and was never transmitted to the mitral area where the second sound was solely due to aortic closure.

During inspiration blood is drawn by the negative pressure in the chest into the right side of the heart from the extrathoracic venous reservoir, but not immediately into the left where the venous reservoir is intrathoracic. The splitting during inspiration has been held to be caused mainly by the

TABLE I

INTERVALS BETWEen ONSET OF QRS OF Electrocardiogram and Mitral VALVE Closure, onset of Mitral Closure and Carotid RISE, and ONSET OF QRS aNd Carotid Rise

\begin{tabular}{|c|c|c|c|c|c|c|c|c|c|c|}
\hline & \multicolumn{3}{|c|}{$\begin{array}{c}\text { Age } \\
\text { (years) }\end{array}$} & \multirow{2}{*}{$\begin{array}{c}\text { Number } \\
\text { of } \\
\text { subjects }\end{array}$} & \multicolumn{2}{|c|}{$\begin{array}{l}\text { Q-M1* } \\
\text { interval }\end{array}$} & \multicolumn{2}{|c|}{$\begin{array}{l}\text { M1-carotid } \dagger \\
\text { rise interval }\end{array}$} & \multicolumn{2}{|c|}{$\begin{array}{l}\text { Q-carotid } \\
\text { rise interval }\end{array}$} \\
\hline & & & & & Range & Mean & Range & Mean & Range & Mean \\
\hline $\begin{array}{c}3-5 \\
6-10 \\
11-16\end{array}$ & $\begin{array}{l}\ldots \\
\cdots \\
\cdots\end{array}$ & $\begin{array}{l}\ldots \\
\cdots \\
\ldots\end{array}$ & $\begin{array}{l}\cdots \\
\cdots \\
\cdots\end{array}$ & $\begin{array}{l}20 \\
25 \\
35\end{array}$ & $\begin{array}{l}0.04-0.05 \\
0.04-0.06 \\
0.04-0.06\end{array}$ & $\begin{array}{l}0.04 \\
0.04 \\
0.05\end{array}$ & $\begin{array}{l}0.02-0.04 \\
0.02-0.04 \\
0.02-0.05\end{array}$ & $\begin{array}{l}0.03 \\
0.03 \\
0.03\end{array}$ & $\begin{array}{l}0.06-0.09 \\
0.06-0.10 \\
0.07-0.10\end{array}$ & $\begin{array}{l}0.07 \\
0.07 \\
0.08\end{array}$ \\
\hline
\end{tabular}

* Indirect electromechanical interval of left ventricle.

$\uparrow$ Indirect isometric time of left ventricle. 
inspiratory increase in stroke volume of the right ventricle with consequent delay in pulmonary closure (Leatham and Towers, 1951; Leatham, 1954), but Boyer and Chisholm (1958) pointed out that aortic closure also moved with respiration. It must be appreciated that the immediate inspiratory increase in stroke volume of the right ventricle is followed after one to three seconds by a similar increase in stroke volume of the left ventricle, and that it is necessary to study the effect of inspiration after a period of apnœa to prevent superimposition of one respiratory cycle on another (Dornhorst, Howard, and Leathart, 1952). This concept was applied to the second heart sound in our adult subjects by Shafter (1960) and produced similar results in the present children. Following halted respiration, inspiration had no effect on A2 but caused an immediate delay in P2, from increased stroke volume of the right ventricle as blood was drawn from the extrathoracic venous reservoir. One to three seconds later, there was delay in A2 as the inspiratory increase in stroke volume reached the left ventricle. At normal respiratory rates, diminished stroke volume of the left ventricle with earlier A2 coincided with the inspiratory increase in stroke volume of the right ventricle and later P2 (wide split), while increased stroke volume of the left ventricle and later A2 coincided with the expiratory diminution in stroke volume of the right ventricle and earlier P2 (narrow split or fusion). In six children, splitting was almost fixed $(0.02 \mathrm{sec}$. on expiration, $0.03 \mathrm{sec}$. on inspiration), but careful measurement established that A2 was not delayed during inspiration, thus excluding atrial septal defect, as discussed later.

Third Heart Sound. A third heart sound averaging $0 \cdot 14 \mathrm{sec}$. after aortic valve closure $(0 \cdot 12$ 0.16 sec., Table II) was heard and recorded at the mitral area in the low frequency phonocardiogram in 50 children, and in 70 per cent of them the third sound was maximal appreciably after inspiration (coinciding with expiration at normal respiratory rates) suggesting a left-sided origin.

In the remaining 30 per cent, however, the magnitude of these low frequency vibrations increased during inspiration suggesting a right-sided origin. The combination of right- and left-sided third sounds produced vibrations of considerable length simulating a short mitral diastolic murmur, and

TABLE II

Onset of a Physiological Third Heart Sound at The Mitral Area

\begin{tabular}{c|c}
\hline $\begin{array}{c}\text { A2-physiological } \\
\text { third sound interval (sec.) }\end{array}$ & $\begin{array}{c}\text { Number of } \\
\text { subjects }\end{array}$ \\
\hline $0 \cdot 12$ & 10 \\
$0 \cdot 13$ & 8 \\
$0 \cdot 14$ & 18 \\
$0 \cdot 15$ & 9 \\
$0 \cdot 16$ & 5 \\
\hline
\end{tabular}

A physiological third heart sound at the mitral area was present in 50 subjects, its onset measuring $0 \cdot 12-0 \cdot 16 \mathrm{sec}$. (mean $0 \cdot 14$ ) after the onset of aortic valve closure.
TABLE III

VARIATIONS With Heart Rate in CAROTID EJECTION TIME, MEASURED FROM CAROTID RISE TO DICROTIC NOTCH DURING EXPIRATION

\begin{tabular}{ll|l|l}
\hline \multirow{2}{*}{ Cycle length } & \multicolumn{2}{|c}{ Carotid ejection time } \\
\cline { 3 - 4 } & & Range & Mean \\
\hline 1.0 &. & $0.28-0.30$ & 0.297 \\
0.9 &. & $0.28-0.30$ & 0.293 \\
0.8 &. & $0.24-0.30$ & 0.284 \\
0.7 &.. & $0.24-0.28$ & 0.266 \\
0.6 &. & $0.22-0.28$ & 0.260 \\
0.5 &. & $0.24-0.27$ & 0.246 \\
\hline
\end{tabular}

the course of time has revealed several errors in misdiagnosing these physiological sounds as a pathological mitral murmur.

Systolic Murmur. A short ejection mid-systolic murmur was maximal in the pulmonary area in 30 children, in the fourth left interspace in 18, in the mitral area in 20 , and equally heard in all areas in 12 (Fig. 1). The murmur was described as grunty or of low frequency in 38, and blowing or of high frequency in 42 subjects. Exercise and excitement tended to increase the loudness of the murmur. The grunty quality was portrayed on the phonocardiogram by regular vibrations of low frequency (100-150 cycles). 
In 55 healthy children the onset of the ejection murmur could be separated from the two components of the first heart sound and occurred $0.08 \mathrm{sec}$. (mean) after mitral valve closure; the murmur could thus have been related to either aortic or pulmonary ejection, or to both. Measurements of the timing of the onset, peak, and duration of the murmur were compared with similar measurements in organic pulmonary and aortic valve disease and atrial septal defect, and by their graphic configuration alone we could not distinguish murmurs in healthy children from murmurs due to organic heart disease.

Carotid Pulse Tracing. The carotid pulse tracing has proved helpful in estimating the left ventricular isometric contraction time, the duration of ejection, and the timing of aortic valve closure. The Q-carotid rise (corrected), which is the interval from the onset of electrical activation of the left ventricle to the opening of the aortic valve, varied from 0.06-0.10 sec. with a mean of 0.07 second, and this interval increased slightly with age (Table I). The carotid ejection time varied from 0.24 to $0.30 \mathrm{sec}$. according to the heart rate; the slower the rate, the longer the carotid ejection time (Table III).

The typical normal pulse in healthy children (Fig. 1) showed an early rapid rising phase (upstroke) followed by a phase of slightly longer duration usually a plateau, but often rising or falling slightly to the incisura which was always well demarcated. The form of the carotid pulse was the same as in young adults (Robinson, 1963).

\section{Discussion}

Elucidation of the cause of systolic murmurs in children is often more difficult than in adults, since localization of the murmur is less accurate and changes in the pulses and in ventricular mass on the electrocardiogram may be more difficult to detect. Under these circumstances accurate interpretation of heart sounds and murmurs is even more important than in adults, and the classification of systolic murmurs into pansystolic regurgitant and midsystolic ejection (Leatham, 1958) may be of value.

A pansystolic murmur immediately indicates that there is organic disease. It may indicate mitral or tricuspid valve disease or a ventricular septal defect or, if maximal in the pulmonary area, a patent ductus arteriosus with some elevation of pulmonary vascular resistance but a left-to-right shunt from a systolic gradient. The key to this classification is the presence or absence of murmur immediately before valve closure, and it is essential to relate left-sided murmurs to aortic closure and right-sided murmurs to pulmonary closure, e.g. a murmur might be pansystolic in relation to A2 but ejection in relation to $\mathrm{P} 2$ (Fig. 2).

The finding of an ejection systolic murmur is much less specific since a physiological ejection murmur is so common in healthy children (Fig. 1). These murmurs may be quite loud (grade 3/6) with increased stroke volume from exercise, excitement, anæmia, vasodilating drugs, or other high output states, or increased stroke volume from sinus bradycardia. A flat chest may be another factor, bringing the great vessels nearer to the chest wall. The low-pitched grunting quality of these murmurs is often stressed, and as a result they are better heard with the bell of the stethoscope than with a rigid diaphragm. By timing the onset of the murmur in relation to ejection we had hoped to decide whether it was aortic or pulmonary, but were unsuccessful. The onset of the murmur was often difficult to define, especially if the first sound was split, and in any case there is no reason why the earliest part of ejection should produce audible vibrations, for maximal flow presumably occurs later. Timing of the peak of physiological ejection murmurs and comparison with known pulmonary or aortic ejection systolic murmurs was equally unrewarding. These observations confirm the clinical impression that ejection murmurs must be identified by their diminution or cessation before their valve closes, rather than by their delayed onset, and that a closer analysis of their shape and timing is not often helpful. Admittedly the ejection murmur of pulmonary stenosis is longer than one from increased pulmonary flow, but this is simply a manifestation of lengthening of systole, the murmur bearing the usual relation to the late pulmonary closure, and also to the fact that the 


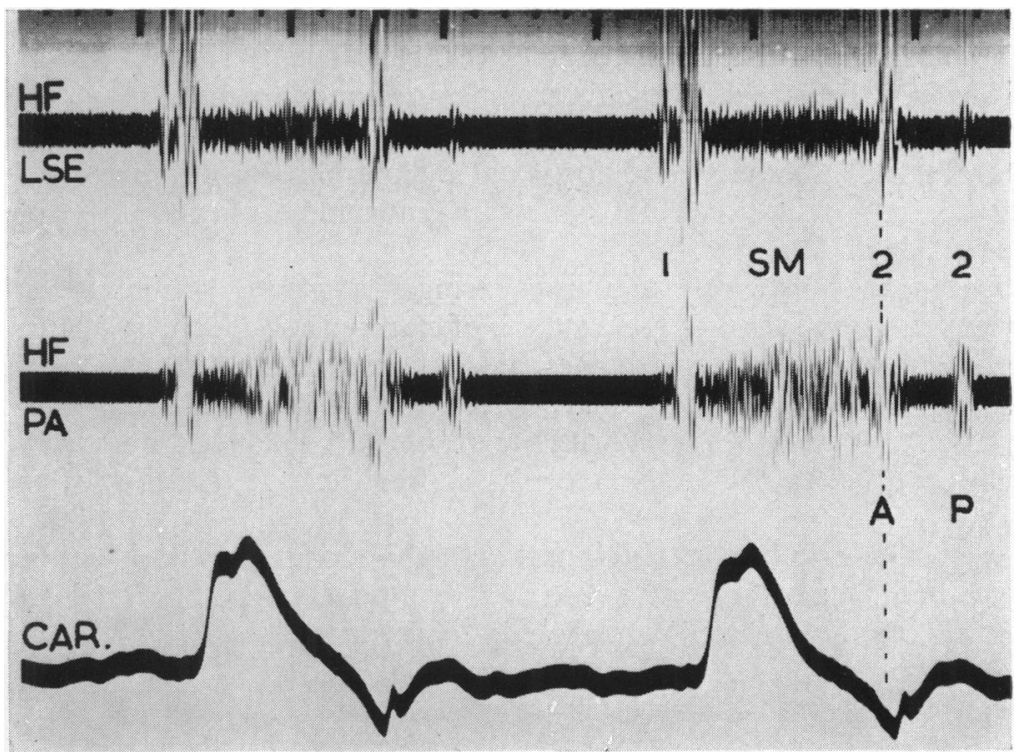

FIG. 2.-Pulmonary stenosis: the systolic murmur may only be described as of ejection pattern in relation to late pulmonary closure. If the murmur had been left-sided it would have been defined as pansystolic in relation to aortic closure. Carotid pulse not taken by the usual linear system but accurate for timing.

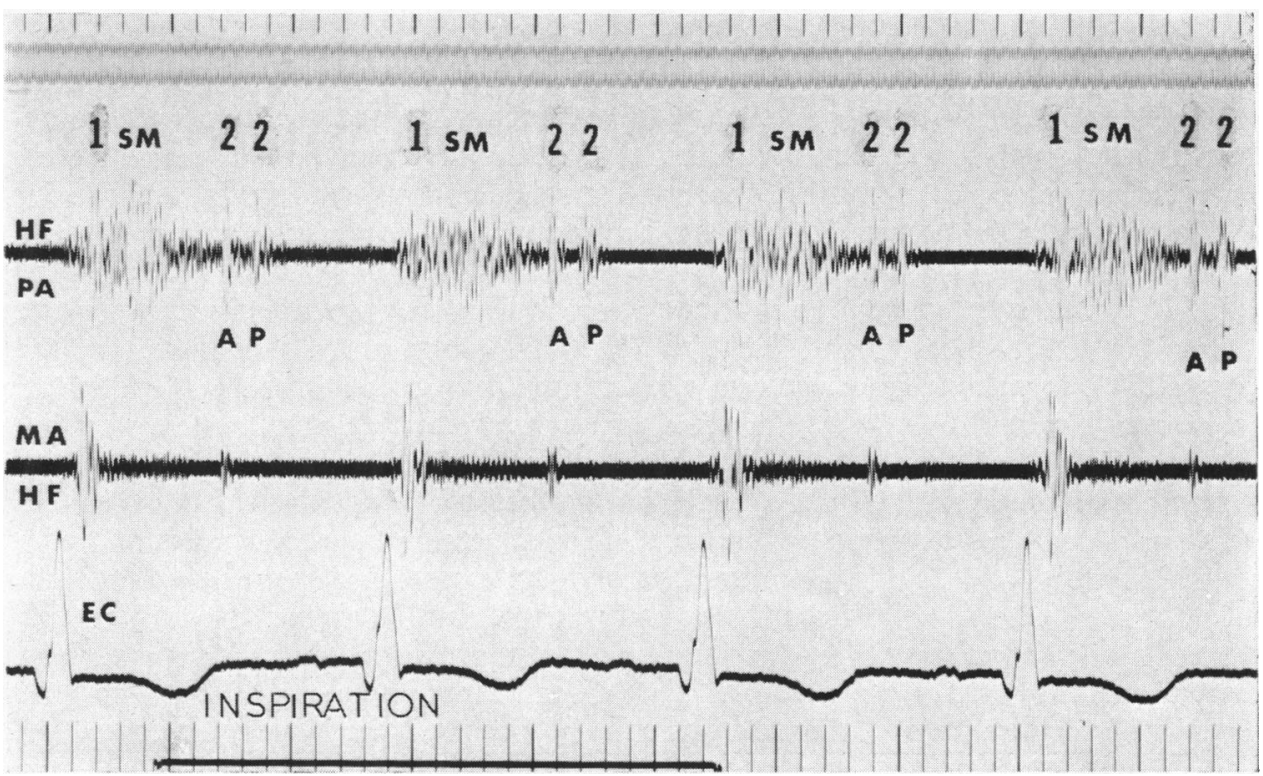

FIG. 3.-Atrial septal defect with left-to-right shunt: the presence of almost fixed splitting of the second sound is diagnostic of atrial septal defect provided that ejection from the right ventricle is not fixed - e.g. from failure - and provided that appreciable respiratory excursion is obtained. The ejection systolic murmur is related to increased pulmonary flow from the left-to-right shunt and is no different in pattern from a physiological ejection murmur. 
systolic vibrations are louder bringing them over the auditory and phonocardiographic threshold for a longer part of ejection. It is not known whether physiological systolic murmurs are from ejection into the aorta or pulmonary artery. Intracardiac phonocardiography shows an ejection murmur in the pulmonary artery and it is stated that it is absent in the aorta (Lewis et al., 1958), though the clinical impression from the site and radiation of these murmurs is that the vibrations often arise from both vessels.

A pulmonary ejection systolic murmur raises the possibility of pulmonary stenosis or an increase in pulmonary flow as in atrial septal defect. In pulmonary stenosis, pulmonary closure is delayed and the width of splitting of the second sound is abnormally wide in the expiratory phase of respiration (Fig. 2) and bears an approximate relation to the right ventricular systolic pressure (Leatham and Weitzman, 1957). In atrial septal defect there are two abnormalities of the second heart sound. Pulmonary closure is abnormally late, and the splitting of the second sound is almost fixed during the respiratory cycle (Leatham and Gray, 1956, and Fig. 3) since variations in stroke volume in the two ventricles are identical owing to the common atrial reservoir (Shafter, 1960). The splitting is not fixed, however, if the interatrial communication is small even if there is a big left-to-right shunt from anomalous veins. In left-to-right shunting ventricular septal defect the ejection murmur from increased pulmonary flow is usually drowned by the loud pansystolic murmur from the defect, except with a large defect and elevated pulmonary vascular resistance resulting in low velocity of flow through the defect. Minute ventricular septal defects may occasionally be associated with a short, loud, high frequency, systolic murmur that is confined to early systole possibly because the defect is in the muscular septum and is closed by muscular contraction in late systole (Leatham and Segal, 1962). The quality of the murmur and its localization to the lower left sternal edge avoid confusion with ejection murmurs and the components of the second sound in ventricular septal defect move normally with respiration though they may be abnormally widely separated.

When a physiological murmur is due to a high output state, both sides of the heart are affected equally and it follows that the splitting is normal. Rare cases of supra-valvular stenosis, pulmonary artery branch stenosis, and abnormalities of the pulmonary valve without a gradient may also be associated with normal splitting of the second sound.

Thus the decision whether a pulmonary ejection systolic murmur is physiological or pathological depends on analysis of the second sound. If the second heart sound becomes single in the expiratory phase of continued respiration, pulmonary stenosis and left-to-right-shunting atrial septal defect are excluded. If the second sound remains split by $0.03 \mathrm{sec}$. or more, ensure that a proper respiratory effect on the circulation is being achieved by asking the patient to breathe more slowly and deeply, and expiratory fusion will almost invariably be obtained in normal subjects: we have seen only two exceptions to this rule. Splitting that remains fixed despite deeper respiration may be caused by inability of a failing right ventricle to increase its stroke volume, as well as by an interatrial communication, and the final test for the latter is that A2 delays as well as P2 during inspiration. Splitting that remains abnormally wide in expiration, increasing normally on inspiration, may be due to early aortic closure, e.g. shortening of ejection time from mitral regurgitation, or to delay in pulmonary closure which may be electrical or mechanical. Delayed pulmonary closure with normal movement may be due to pulmonary valve or infundibular stenosis, selective overloading of the right ventricle as from anomalous venous return without a large atrial septal defect, dilatation of the pulmonary ring (Schrire and Vogelpoel, 1962), or to delay in electrical activation or spread from complete right bundle-branch block: there may, however, be no electrocardiographic hint of delay for we have found abnormally wide splitting of the second sound in left-to-right shunting ventricular septal defect with a normal electrocardiogram, but there was a prolonged electromechanical interval of the right ventricle (Leatham and Segal, 1962). Reversed splitting of the second sound (disappearance of split on inspiration) indicates that pulmonary closure precedes aortic and almost invariably indicates prolongation of left ventricular systole-often from left bundle-branch block, aortic stenosis, or hypertension (Leatham, 1954).

An aortic origin of an ejection systolic murmur is suggested if the murmur is as loud or louder 
in the aortic area than the pulmonary area and is well transmitted to the mitral area where indeed it may be maximal. Transmission to the neck is less useful, for a short murmur during maximal ejection in mid systole may normally be heard over the carotids. Aortic stenosis will have been diagnosed on the carotid pulse by its slow rise and prolonged ejection (sometimes not obvious in children), often confirmed by reversed splitting of the second sound or a single second sound, and evidence of left ventricular hypertrophy. The association of an aortic sytolic murmur (no diastolic) with a sharp pulse and left ventricular hypertrophy was puzzling in the past, but is now known to be commonly due to muscular infundibular obstruction (P. Wood, 1959, personal communication). Increased stroke flow is an important cause of an aortic ejection murmur and aortic regurgitation must be listened for. A left-to-right shunt through a duct or aorto-pulmonary fistula may be silent under some circumstances, but the increased aortic flow usually produces an ejection systolic murmur. Very slow heart rates with big stroke volumes cause both an aortic and a pulmonary ejection systolic murmur.

The differentiation of a physiological ejection murmur in children from one due to minimal roughening of the aortic valve (often rheumatic), without significant stenosis or regurgitation may be very difficult and one still has to rely on the intensity of the murmur particularly in the aortic area. A murmur that is grade $2 / 6$ or more in the aortic area, as loud or louder in the mitral area, and less loud in the pulmonary and lower left sternal edge areas is suspicious of aortic disease, but some have disappeared as we have watched them over the years. An aortic ejection sound may draw attention to aortic valve disease even when minimal, particularly aortic regurgitation or a bicuspid valve; but some ejection sounds appear to be innocent. In children and young adults an aortic ejection murmur indicating a mimimal defect, which is unimportant hæmodynamically, requires to be noted because of the possibility of the development of bacterial endocarditis. In the older agegroups little notice can be taken of a soft aortic ejection murmur because of the high frequency of unimportant thickening of the base of the aortic cusps in association with aortic atheroma (Evans, 1954 ) as their cause. The flow of blood through a coarctation may mimic an aortic valve murmur but should be suspected by its wide radiation anteriorly and to the back, and sometimes its later timing can be appreciated.

Finally, in assessing the significance of an ejection systolic murmur, all the other physical signs must be taken into account, especially the cardiac output, for reduced forward stroke flow from heart failure, often with mitral regurgitation, may greatly diminish even the systolic murmur of severe aortic stenosis.

\section{SUMmaRY}

The auscultatory and phonocardiographic findings in 80 healthy children are described with special emphasis on the differentiation of the physiological ejection murmur from pathological systolic murmurs.

Measurements are given for the interval between onset of QRS and first sound and carotid rise, duration of carotid ejection, and width of splitting of the first and second sounds. Based on these measurements, estimates are given of the electromechanical interval and isometric contraction time of the left ventricle.

\section{REFERENCES}

Boyer, S. H., and Chisholm, A. W. (1958). Circulation, 18, 1010.

Braunwald, E., Fishman, A. P., and Cournand, A. (1956). Circulat. Res., 4, 100.

-, Moscovitz, H. L., Amram, S. S., Lasser, R. P., Sapin, S. O., Himmelstein, A., Ravitch, M. M., and Gordon, A. J. (1955). J. appl. Physiol., 8, 309.

Dornhorst, A. C., Howard, P., and Leathart, G. L. (1952). Circulation, 6, 553.

Duchosal, P. W., Ferrero, C., Leupin, A., and Urdaneta, E. (1956). Amer. Heart J., 51, 861.

Evans, W. (1954). Cardiography, 2nd ed. Butterworth, London.

Harris, T. N. (1955). Amer. Heart J., 50, 805.

- and Friedman, S. (1952). Amer. Heart J., 43, 707. 
Leatham, A. (1952). Brit. med. Bull., 8, 333.

(1954). Lancet, 2, 607.

(1958). Lancet, 2, 703 and 757.

- and Gray, I. (1956). Brit. Heart J., 18, 193.

-, and Segal, B. (1962). Circulation, 25, 318.

- , and Towers, M. (1951). Brit. Heart J., 13, 575.

- and Weitzman, D. (1957). Brit. Heart J., 19, 303.

Lessof, M., and Brigden, W. (1957). Lancet, 2, 673.

Lewis, D. H., Deitz, G. W., Wallace, J. D., and Brown, J. R. (1958). Circulation, 18, 991.

Mannheimer, E. (1940). Acta paediat. (Uppsala), 28, Suppl. 2.

McKee, M. H. (1938). Amer. Heart J., 16, 79.

Reinhold, J., and Rudhe, U. (1957). Brit. Heart J., 19, 473.

Robinson, B. (1963). Brit. Heart J., 25, 61.

Schrire, V., and Vogelpoel, L. (1962). Amer. Heart J., 63. 501.

Shafter, H. A. (1960). Amer. J. Cardiol., 6, 1013.

Still, G. F. (1909). Common Disorders and Disease of Childhood. Frowde, London.

Weissler, A. M., Leonard, J. J., and Warren, J. V. (1958). Circulation, 18, 165.

Wells, B. (1957). Brit. Heart J., 19, 129.

Wiggers, C. J., and Clough, H. D. (1919). J. Lab. clin. Med., 4, 624. 